This item was submitted to Loughborough's Research Repository by the author.

Items in Figshare are protected by copyright, with all rights reserved, unless otherwise indicated.

\title{
Faces in motion: age-related changes in eyewitness identification performance in simultaneous, sequential, and elimination video lineups
}

\section{PLEASE CITE THE PUBLISHED VERSION}

http://dx.doi.org/10.1002/acp.1808

\section{PUBLISHER}

(c) Wiley

\section{VERSION}

AM (Accepted Manuscript)

\section{PUBLISHER STATEMENT}

This work is made available according to the conditions of the Creative Commons Attribution-NonCommercialNoDerivatives 4.0 International (CC BY-NC-ND 4.0) licence. Full details of this licence are available at: https://creativecommons.org/licenses/by-nc-nd/4.0/

\section{LICENCE}

CC BY-NC-ND 4.0

\section{REPOSITORY RECORD}

Humphries, Joyce E., Robyn Holliday, and Heather D. Flowe. 2019. "Faces in Motion: Age-related Changes in Eyewitness Identification Performance in Simultaneous, Sequential, and Elimination Video Lineups". figshare. https://hdl.handle.net/2134/20188. 
Faces in motion 1

Faces in Motion: Age-Related Changes in Eyewitness Identification Performance in Simultaneous, Sequential, and Elimination Video Lineups

Joyce E. Humphries, Robyn Holliday, \& Heather D. Flowe University of Leicester, School of Psychology

Address ms. correspondence to: Joyce E. Humphries jeh42@le.ac.uk School of Psychology

Forensic Section

University of Leicester 106 New Walk

Leicester, UK

LE1 7EA 
Faces in motion 2

\begin{abstract}
The identification performance of children ( 5 to 6 years, $n=180$; 9 - to 10 - years, $n=$ $180)$ and adults $(n=180)$ was examined using three types of video lineup procedures: simultaneous, sequential and elimination. Participants viewed a videotaped staged theft and then attempted to identify the culprit from a target-present or target-absent video lineup. Correct identifications in simultaneous and elimination video lineups did not differ as a function of age. The sequential video lineup was associated with a reduction in correct identifications for both child groups compared to adults. With respect to the target-absent lineup condition, the video elimination lineup was associated with an increase in correct rejection rates for adult witnesses. Age was also significantly associated with accuracy. Differences in correct rejection rates were observed between adults and children and also between the two child groups. Implications and future directions are discussed.
\end{abstract}


Faces in motion 3

Faces in Motion: Age-Related Changes in Eyewitness Identification Performance in Simultaneous, Sequential and Elimination Video Lineups

Eyewitness identifications play a pivotal role in criminal prosecutions and in some criminal investigations, children are often the only source of a positive suspect identification (Pike, Brace, \& Kynan, 2002, Juvenile Offenders and Victims National Report, 2006). Research in many domains has found that the memories of younger children are more prone to error in some circumstances compared to other age groups (e.g., Bruck \& Ceci, 1999; Ceci \& Bruck, 1993, 1995; Goodman, 2006; Holliday, Reyna, \& Hayes, 2002; but see Brainerd, Reyna, \& Ceci, 2008). In particular, eyewitness identification research studies typically show that compared to adults, children (5- years and over) are as likely as adults to correctly identify the culprit when shown a targetpresent lineup (e.g., Goodman \& Reed, 1986; Lindsay, Pozzulo, Craig, Lee \& Corber, 1997; Marin, Holmes, Guth, \& Kovac, 1979; Parker, \& Carranza, 1989; Parker \& Ryan, 1993; Pozzulo \& Balfour, 2006), but when shown a target-absent lineup (i.e., lineup containing only innocent persons), children (up to the age of 14-years) are more likely to make a false identification (i.e., identify an innocent person) (Beal, Schmitt, \& Dekle, 1995; Davies, 1996; Dekle, Beal, Elliott, \& Huneycutt, 1996; Parker \& Carranza, 1989; 
Parker \& Ryan, 1993; Pozzulo \& Balfour, 2006; Pozzulo \& Dempsey, 2006; for reviews see Pozzulo, 2007; Pozzulo \& Lindsay, 1998). Yet, other researchers have found that older children's (10 - to 14 year-olds) identification performance in target-absent lineups is similar to that of adults (Leippe, Romanczyk, \& Manion, 1991; Pozzulo \& Lindsay, 1997; Pozzulo \& Warren, 2003, Experiment 2).

\section{Lineup identification procedures}

In an attempt to improve children's and adult's identification accuracy a number of innovative lineup procedures have been developed. The two most common of these are the simultaneous lineup (i.e., all lineup members are presented at once) and the sequential lineup (i.e., lineup members are presented serially) (for reviews see, Clark \& Godfrey, 2009; Steblay, Dysart, Fulero, \& Lindsay, 2001; Steblay, Dysart, \& Wells, 2011). The sequential lineup has typically been shown to reduce adult witnesses false identification rates without affecting correct identification rates compared to a simultaneous lineup (e.g., Cutler \& Penrod, 1988; Dysart \& Lindsay, 2001; Kneller, Memon \& Stevenage, 2001; Lindsay \& Bellinger, 1999; Lindsay, Lea, \& Fulford, 1991a; Lindsay, Lea, Nosworthy, Fulford, Hector, LeVan \& Seabrook, 1991b; MacLin, Zimmerman \& Malpass, 2005; Sporer, 1993). There is some evidence however, that the decrease in adult's false identifications in sequential lineups is associated with a reduction in correct suspect identifications (Clark \& Godfrey, 2009; Steblay, et al., 200; Steblay et al., 2011).

The most prevalent explanation for the sequential lineup advantage for adult witnesses is that a sequential lineup encourages a witness to shift from using a relative judgment strategy (a witness compares lineup members to one another and then chooses the one that most resembles the eyewitness' memory of the perpetrator) to an absolute judgment 
strategy (a witness compares each lineup member to their memory of the suspect) (Lindsay $\&$ Wells, 1985). Other researchers have challenged this explanation arguing that it is a shift in decision criteria rather than a shift in decision process (i.e. from a relative to an absolute decision strategy) that accounts for witnesses' higher correct rejection rates in a sequential line-ups (Ebbesen \& Flowe, 2002; Meissner, Tredoux, Parker, \& MacLin, 2005). Additionally, a recent meta-analysis has indicated that the sequential lineup may not be more effective than the simultaneous lineup when certain methodological factors are controlled (McQuiston-Surrett, Malpass, \& Tredoux; 2006). Moreover, children's false identification rates continue to be considerably higher than those of adults for both lineup procedures (Parker \& Ryan, 1993; Pozzulo \& Lindsay, 1998; Pozzulo, et al., 1997; Steblay et al., 2001). For example, Parker and Ryan (1993) found that children's (8- to 11-year olds) false identification rates were not reduced with a sequential compared to simultaneous lineup. Children were also found to make more multiple choices from sequential lineups.

In an effort to reduce children's false identification rates, Pozzulo and Lindsay (1999) developed the elimination lineup. The elimination lineup utilises a simultaneous presentation but the identification process is divided into two stages. First, a witness is asked to select the line-up member who most resembles the culprit (relative judgment), and is then asked to decide whether the chosen lineup member is the culprit or not (absolute judgment). Pozzulo and Lindsay proposed that children's lower accuracy when the target is absent from the lineup may be due to them failing to implement the second judgment. 
Pozzulo and Lindsay (1999) compared the identification performance of 10- to 11-year olds, 12- to 14-year olds, and adults in simultaneous lineups with several variations of the elimination procedure. These included, the inclusion of modified instructions (highlighted the consequence of making a false identification), the fast elimination lineup (witness is asked to select the line-up member who most resembles the culprit), and the slow elimination lineup (a witness is asked to eliminate lineup members one by one by selecting the photo who look least like the culprit until one photo remains). In target-present conditions, children's correct identification rates remained the same regardless of the procedure viewed. In target-absent conditions, the slow elimination procedure was the only procedure which failed to produce a reduction in children's false identification rates compared with the simultaneous lineup.

More recently, the beneficial effects of the elimination procedure have also been shown to extend to pre-schoolers (e.g., Pozzulo, Dempsey, \& Crescini, 2009) and adults (e.g., Pozzulo \& Balfour, 2006; Pozzulo et al., 2008). For example, Pozzulo and Balfour (2006) compared the identification performance of 8- to 13-year olds and adults in simultaneous and fast elimination lineup procedures. Results indicated that for both age groups, the elimination lineup procedure was more effective than the simultaneous lineup at reducing false identification rates without any corresponding decrease in correct identification rates. Thus, the available evidence indicates that children's and adults identification performance can be facilitated by the elimination lineup procedure. 
The evidence presented so far has only focused on the influence of lineup presentation procedure on witnesses' identification performance. Typically, identification evidence is obtained from photo lineups, and to a much lesser extent, live lineup parades (Wells, Memon, \& Penrod, 2006). In the UK, however, identification evidence gathering requires that video lineups are conducted (Police and Criminal Evidence Act (PACE), 1984; code of practice D, 2008). Video lineups are always presented sequentially (PACE, 1984; code of practice D, 2008), but differ from the sequential lineup procedures commonly implemented in the literature on a number of measures. Specifically, (a) video lineups almost always consist of moving image sequences which depict a face moving in a 180 degree motion, from a full frontal pose to left profile pose, right profile pose and a final full frontal pose position; and, (b) a witness is required to view the entire lineup at least twice before providing an identification response. Research has indicated that identification performance in sequential lineups is reduced when the lineup is not terminated after the first "yes" response (McQuiston-Surrett et al., 2006; MacLin \& Phelan, 2007; Steblay, 2010). Hence, here we focus on the use of moving images in different lineup procedures as an aid for improving children's identification performance.

Why would moving face images be expected to improve identification performance? It is highly unlikely that a witness will only see a single view of a culprit's face. Therefore, moving images may present a witness with important information about the suspect's appearance which may be lost when static images are presented (e.g., see, Bruce, Burton, \& Hancock, 2007; O’Toole, Roark \& Adbi, 2002; Ullman, 1979; Valentine, Darling, \& Memon, 2007). Additionally, according to transfer-appropriate 
processing theory, memory accuracy will be enhanced if encoding and testing conditions match (Morris, Bransford, \& Franks, 1977).

Research comparing the use of moving and static lineup images on adult witnesses' identification accuracy has, however, produced mixed findings. Although, correct identification rates in video and static lineups remain comparable (Cutler \& Fisher, 1990; Darling, Valentine, \& Memon, 2008; Valentine, Darling, \& Memon, 2007), in target-absent conditions, video lineups have been associated with a reduction in false identifications when compared to static lineups (Cutler \& Fisher, 1990; Valentine et al., 2007). However, the associated reduction in false identifications in target-absent lineups with video lineups has not always been observed (Darling et al., 2008).

Presentation of lineup members using moving images with child witnesses has also produced inconsistent findings (Beresford \& Blades, 2006; Havard, Memon, Clifford, \& Gabbert, 2009). Beresford and Blades (2006) examined the identification performance of 6- to 7-year-olds and 9- to 10-year-olds in photo and moving image lineups (video lineups), following the viewing of a staged theft video. Six different lineup procedures were used; standard photo simultaneous, modified instruction photo simultaneous, modified instruction photo elimination (presented simultaneously), standard video sequential, modified instruction video sequential, and modified instruction video elimination (presented sequentially). For target-present or target-absent conditions no age effects were observed. The use of cautioning instructions improved children's correct rejection rates (without lowering their correct identifications) in both photo and video lineups. In contrast to previous findings however, the elimination lineup was not associated with a reduction in false identification rates. In addition, while, correct 
identification rates were comparable across the photo lineup procedures, for video lineups, the elimination lineup procedure produced a reduction in correct identifications.

More recently, however, video lineups have been shown to facilitate adolescent's identification accuracy (Harvard et al., 2009). Havard and colleagues (2009) introduced the target to 7- to 9-year-olds and adolescents (13- to 15 years) using a live event, and subsequently presented children with either a video or photo sequentially administered lineup. In target-present conditions, correct identification rates were the same regardless of lineup presentation format (i.e., video or photo) or age. In target-absent lineups however, video lineups increased correct rejection rates compared to photo lineups, but for the adolescent group only. Havard et al. (2009) concluded that due to their poorer processing resources, younger children may have been less able than the older children to effectively use the additional information provided when faces are viewed in motion (see also Skelton \& Hay, 2008).

\section{The present study}

In sum, based on the extant literature it would appear that younger children's (under 10-years) identification performance is not facilitated by viewing moving images. However, the majority of studies examining the beneficial effects on movement on children's identification accuracy have employed sequentially administered lineups, and the sequential procedure is particularly problematic for child witnesses. The elimination lineup has been shown to be effective at reducing children's false identification rates while maintaining an adult level of correct identifications. In contrast, however, children's identification performance is reduced when a sequentially administered 
elimination lineup that incorporates moving images is viewed (Beresford \& Blades, 2006). Beresford and Blades (2006) argued that children's poorer performance may be related to the complexity of the instructions required for this lineup procedure. Therefore, an elimination lineup procedure which simplifies the complexity of the instructions required could aid children's identification performance when used in combination with moving images.

Therefore, alongside a sequentially administered video lineup, the effects of two novel video lineup procedures were investigated, including a simultaneous video lineup and a simultaneously administered video elimination lineup. For each video lineup procedure, target-present and target-absent conditions were employed. An adult group and two child groups (5- to 6-year olds and 9- to 10-year olds) were included. Considering the somewhat inconsistent findings in the literature a number of tentative predictions were made: 1) correct identification rates would remain comparable for each age-group across the simultaneous and elimination video lineups, 2) correct identification rates will be lower in sequential video lineups, 3 ) adults would have a higher correct rejection rate than children across the simultaneous and elimination video lineups, and 3) children's correct rejection rates would be facilitated the most with the elimination video lineup.

Method

\section{Participants}

Approval for this study was granted by the University ethical review research committee. A total of 180 adults $(18-49$ years of age, $M=20$ years. $\mathrm{SD}=3.41)$ were recruited from a psychology undergraduate course and received course credit for their 
participation. None of the students had received lectures specifically related to the face recognition or the lineup identification literature. Children 5- to 6-year olds $(\mathrm{N}=180, M$ $=5.8$ years, $S D=.3$ years $)$ and 9 - to 10 -year-olds $(\mathrm{N}=180, M=9.8$ years, $S D=.3$ years $)$ were recruited from primary schools in the South East of England. Consent from head teachers and legal guardians were obtained.

Design

A 3 (video lineup presentation: simultaneous, sequential, elimination) x 3(Age: 5to 6-year-olds, 9- to 10-year olds, adults) x 2 (lineup type: target-present, target-absent) between-subjects design was employed. Dependent measures were lineup identification responses. In target-present conditions, there were three possible identification responses: (1) a correct identification, (2) a false alarm, or (3) an incorrect rejection. In target-absent line-ups, only two identification decisions were possible, either: (1) a correct rejection, or (2) a false alarm.

\section{Materials}

Event. A number of researchers have questioned the ecological validity of videotaped crime simulations often used in laboratory-based studies (Ihlbaek, Love, Eilertsen \& Magnussen, 2003; Tollestrup, Turtle, \& Yuille, 1994; Yuille, 1993). Recent evidence however, has indicated that witnesses identification performance is not influenced by the mode of exposure (live versus videotaped) used to present the target (Pozzulo, Crescini, \& Panton, 2008). Hence, the present study implemented a videotaped nonviolent theft, which was specifically designed to be appropriate for all participant age groups. The film depicted a young male in his early 20 s acting suspiciously whilst browsing in a clothing store. Also depicted in the film was a female (22 years old) who was looking at some 
items on an accessory stand. The young woman's face was never shown, as her back was always to the camera. The young man, noticing that the woman's bag was open, reached in and stole the woman's purse and placed it into his own bag before leaving the shop in full view of the camera. The woman remained unaware that her purse had been taken. The event lasted for $75 \mathrm{~s}$. The culprit remained in view for the entire recording and was filmed from various angles: close-up, left and right profile, front and back, and threequarters.

Lineup construction. A description of the target was obtained from an additional 12 participants (who were the same age and ethnicity as the target). These participants were shown a photograph of the target (for approximately $8 \mathrm{~s}$.), the photograph was then removed, and participants were asked to provide a written description of the person they had just seen. These descriptions were used to generate a modal description of the target (cf., Lindsay et al., 1994). The final description was, “white male, early 20's, dark short hair, medium build." This description was then used as the basis for selecting a pool of University student volunteers from which the lineup foils were chosen.

A short motion image clip was created for each volunteer. The backdrop, focal distance, and lighting conditions were held constant across the image clips. Image clips were colour, head-and-shoulder shots. The clips depicted a face moving in a 180 degree motion, from a full frontal pose to left profile pose, right profile pose and a final full frontal pose position. The entire film sequence lasted approximately $15 \mathrm{~s}$ for each clip.

From this pool of volunteers, eight lineup foils were chosen based on their resemblance to the culprit by two independent judges. For the static lineup conditions, a still image of each lineup member was used. As no specific foil was designated as the 
target-replacement, lineup foils were counterbalanced across conditions. Evidence indicates that the position of the target may be critical, specifically in sequential lineups (Carlson, Gronlund, \& Clark, 2008; Clark \& Davey, 2005: Ebbesen \& Flowe, 2002; Gronlund, Carlson, Dailey, \& Goodsell, 2009), hence the position of the target was held constant across participants. The target always appeared in position four.

The lineups were pretested using the mock witness paradigm. Twenty-five mock witnesses were provided with the modal description of the target and asked to select the person from the lineup who they thought was the best fit to the description. The proportion of mock witnesses who identified the target from the lineup was .28 . This was not found to be significantly different to the proportion expected by chance alone for a 9person lineup $(.11 ; \alpha=.05$ level). Lineup size was also measured using Tredoux's E' (Tredoux, 1998). Tredoux' E (Tredoux, 1998), which is a measure of the effective size of a lineup that takes into account the distribution of mock witness choices across lineup members. Tredoux's E' (5.53) revealed that two lineup foils failed to draw any mock witness choices. These two lineup foils and one additional foil were removed and a 6person target-present lineup resulted. This additional foil, together with the five lineup foils used in the target-present were used to construct the target-absent lineups.

\section{Lineup instructions and procedures}

Lineup instructions were based on those used by Pozzulo and Lindsay (1997, 1999), with some minor adjustments made to make them more appropriate for use with moving clips. For all lineup conditions participants were not permitted to, a) move 
backwards or forwards through the lineup, b) to pause a video clip, or c) an additional look at an individual lineup member's video clip.

Simultaneous video lineup. In the simultaneous video lineup condition, the six image clips were presented in a 3 x 2 array. A corresponding number $(1-6)$ and the word play appeared beneath each clip. Each participant was provided with the following verbal instructions:

"I am now going to show you some pictures. The man from the film who stole the woman's purse may be in the pictures that I show you or he may not. I am first going to ask you to look at each picture separately. Each of the pictures is a moving picture. Please look at each picture very carefully as pictures may look very similar to each other."

After receiving these instructions, a full-frontal static picture for each lineup member was presented. Each clip was played by the experimenter sequentially in numerical order, with the next clip being shown only when the previous clip had ended. A full frontal static picture of each lineup member was again displayed after each clip had played. After all lineup members had been viewed participants were then asked to provide their identification decision.

Elimination video lineup: Image clips were displayed in the same way as the simultaneous lineup procedure, but the word eliminate also appeared beside the word play beneath each lineup member. Each participant was provided with the following verbal instructions: 
"I am now going to show you some pictures. The man from the film who stole the woman's purse may be in the pictures that I show you or he may not. I am first going to ask you to look at each picture separately. Each of the pictures is a moving picture. Please look at each picture very carefully as pictures may look very similar to each other. When you have seen all of the pictures I want you to tell me which one of the pictures looks most like the man in the film who stole the woman's purse."

The elimination lineup proceeded in a similar manner as the simultaneous lineup, with each lineup member's image clip being shown separately before the participant was asked to select the picture that looked most like the man from the film. Once a lineup member was selected, the five lineup members that had been eliminated were no longer visible on the computer screen. Only the chosen lineup member remained visible. Participants then received the following verbal instructions:

"I asked you to pick the picture that looked most like the man in the film who stole the woman's purse. Now I am going to let you see the clip again and I would like you to think carefully about what the man in the film looked like. If this is the man from the film who stole the woman's purse then I would like you to tell me that it is him. If it is a picture somebody who just looks like him, I want you to tell me that it is not the man from the film."

After viewing the chosen lineup member's video clip participant's identification response was recorded. 
Sequential lineup. For the sequential lineup the six image clips were presented separately such that only one lineup member was visible at all times. The intrinsic nature of the computer presentation of the sequential lineup ensured that participants were unable to deduce the number of to-be-presented lineup members. The following instructions were read aloud to participants:

"I am now going to show you some pictures. The man from the film who stole the woman's purse may be in the pictures that I show you or he may not. You will be shown one picture at a time. Each of the pictures is a moving picture. Please look at each picture carefully as you will only get to see each picture once and you will not be able to go back through the pictures. Therefore, it is important that you tell me as soon as you think you see a picture of the man from the film. Once you have chosen a picture, I will stop, and you will not be allowed to see any additional pictures."

Following these instructions, the experimenter played the image clip of the first lineup member. When the image clip finished playing, the experimenter asked the participant, "Is this the man you saw in the film?" If the participant indicated that it was not, the experimenter showed the next lineup member in the sequence. This procedure continued until the participant made a positive identification, (in which case the lineup procedure ended) OR until the participant reached the end of the lineup. If a participant reached the end of the lineup without making a positive identification, a "not there" decision was recorded. 


\section{Procedure}

The experimenter showed the film to each participant separately. Participants were asked to attend to the laptop screen (17-inches) carefully as a video would be shown and they would be asked some questions about the film later. Immediately after viewing the film, participants completed a filler task (pencil-and-paper puzzles) for approximately 10 minutes. Next, participants then viewed a simultaneous, elimination, or sequential lineup procedure, that was either target-present or target-absent. Before the lineup was presented, the experimenter enquired if the participant had understood the lineup instructions.

\section{Results}

\section{Identification accuracy}

The percentage of identification responses for each lineup procedure and each age group are presented in Table 1. Identification responses were analysed with Hierarchical Loglinear Analysis (HILOG), with age group and lineup procedure as the predictors. The target-present and target-absent conditions were analysed separately, as identification decisions may be driven by different processes depending on the target's presence in the lineup (Pozzulo \& Lindsay, 1999). Significant results were further analysed using the chi square test of association. Following Wright (2002), we calculated odds ratios (OR) to measure effect sizes.

\section{PLEASE INSERT TABLE 1 ABOUT HERE}

\section{Target-present lineups}


For target-present lineups, $60.7 \%$ of participants correctly identified the target, $23.7 \%$ incorrectly choose an innocent foil, and $15.6 \%$ incorrectly stated that the suspect was not present and therefore incorrectly rejected the lineup. An initial hierarchical loglinear analysis (HILOG) with age (5-6 years, 9-10 years, adults), lineup procedure (simultaneous, sequential, elimination), and identification decision (correct identification, foil identification, incorrect rejection) as factors was preformed. This analysis revealed that more than $20 \%$ of the cells in the contingency table had an expected frequency of less than 5 (i.e., the assumption required to perform a loglinear analysis were violated). To increase cell frequencies all erroneous identification responses (foil identifications and incorrect rejections) were combined. Hence, the subsequent hierarchical loglinear analysis (HILOG) was conducted with age (5-6 years, 9-10 years, adults), lineup procedure (simultaneous, sequential, elimination), and identification decision (correct or incorrect) as factors. This analysis revealed a model that retained all effects (Figure 1). The likelihood ratio of this model was $\left(\chi^{2}(0, N=270)=0, p=1\right)$. This indicated that the highest-order interaction (the lineup $\mathrm{x}$ age $\mathrm{x}$ identification accuracy) was significant, $\left(\chi^{2}\right.$ $(1, N=270)=10.36, p<.05)$.

\section{PLEASE INSERT FIGURE 1 ABOUT HERE}

To further analyse this interaction effect, correct identification rates for each age group were examined within lineup procedure. As expected, age-related differences in correct identification rates in simultaneous and elimination lineup procedures were not observed. There was however, a main effect of age on correct identifications in the 
sequential lineup condition, $\left(\chi^{2}(2, N=90)=17.90, p<.001\right)$. Adults were more likely to correctly identify the target in a sequential lineup than 5 - to 6 year-olds, $\left(\chi^{2}(1, N=60)=\right.$ $17.38, p<.001)$, and 9- to 10 -year-olds, $\left(\chi^{2}(1, N=60)=8.86, p<.01\right)$ the two groups of children did not differ, $\left(\chi^{2}(1, N=60)=1.76, p<.05\right)$. Adults were 2.78 times more likely than 5 - to 6 year olds and 1.79 times more likely than 9- to 10 year olds to correctly identify the target in a sequential lineup.

Additional analyses were performed within each age group to assess whether a particular lineup procedure was more effective at increasing correct identifications. For 5to 6-year olds, there was a significant association between correct identifications and lineup procedure, $\left(\chi^{2}(2, N=90)=6.49, p<.05\right)$. Correct identifications of the target were less likely with the sequential video lineup than the simultaneous video lineup, $\left(\chi^{2}\right.$ $(1, N=60)=5.45, p<.05)$, and the elimination video lineup, $\left(\chi^{2}(1, N=60)=6.49, p<\right.$ $.05)$. For 5-to 6-year olds, the odds of correctly identifying the target were 2 times higher with a simultaneous lineup and 1.89 times higher with the elimination lineup when compared to the sequential lineup condition. As expected, differences in correct identification rates between simultaneous (60\%) and elimination (57\%) lineups were not observed for 5- to 6-year olds. Lineup procedure condition did not influence correct identification rates for adults or 9- to 10-year olds.

\section{Target-absent lineups}

Overall, for target-absent lineups $31.7 \%$ of 5- to 6-year olds, $57.8 \%$ of 9- to 10 year olds, and $72 \%$ of adults correctly indicted that the target was absent from the lineup. 
A Hierarchical loglinear analysis (HILOG) was conducted with age (5-6 years, 910 years, adults), lineup procedure (simultaneous, sequential, elimination), and identification decision (correct rejection, false alarm) as factors. Lineup procedure did not contribute to the final model, which retained the variables age group and identification accuracy. The likelihood ratio of this model was, $\left(\chi^{2}(12, N=270)=4.36, p=.98\right)$.

Age was significantly associated with identification accuracy, $\left(\chi^{2}(2, N=270)=\right.$ $27.68, p<.001)$. Follow-up $\chi^{2}$ tests indicated that adults were significantly more likely to make a correct rejection than the 5 - to 6 -year-olds, $\left(\chi^{2}(1, \mathrm{~N}=180)=27.25, p<.001\right)$ and 9- to 10 -year olds, $\left(\chi^{2}(1, \mathrm{~N}=180)=4.69, p<.05\right)$. Adults were 2.22 times more likely than 5 - to 6 year olds, and 1.28 times more likely than 9- to 10-year-olds to make a correct lineup rejection. Correct rejection rates were also found to differ significantly across the child groups, $\left(\chi^{2}(1, N=180)=9.49, p<.01\right)$. The 9 - to 10 year-olds were 1.72 times more likely to correctly reject a lineup than 5- to 6-year-olds.

Further analyses were performed within each age group to determine whether a particular lineup procedure was more effective at increasing correct identifications. The difference between adults correct rejection rates in simultaneous and elimination lineups was marginally significant, $\left(\chi^{2}(1, N=60)=2.86, p=.09\right)$. Adults were 1.33 times more likely to make a correct lineup rejection with the video elimination lineup than the simultaneous lineup. No other significant effects were found.

\section{PLEASE INSERT TABLE 2 ABOUT HERE}

Survival rate (Target-present, elimination lineup) 
The elimination procedure also provides information on 'survival status,' that is, the rate that a lineup member is selected during the first judgment (Pozzulo \& Lindsay, 1999). Pozzulo and Lindsay argued that if the suspect does not survive the first judgment then the probability that the suspect is innocent increases. The survival rate for each lineup member following the first judgment and the identification rate following the second judgment are presented in Table 2. The target was selected during the first judgment at a rate of .60 for the 5- to -6-year olds, a rate of .80 for the 9 - to 10 -year olds, and a rate of .93 for the adults. For all age groups the target survived the first judgment at a significantly higher rate than all other lineup members. For adult witnesses, the target was 1.47 times more likely to survive judgment one than be subsequently identified in the video elimination lineup, $\left(\chi^{2}(1, \mathrm{~N}=60)=7.95, p<.01\right)$. No significant differences between the survival rate and identification rate for 5- to 6-year olds (.60 versus .57) and 9- to 10 -year olds (.80 versus .63) were found. Table 2 also provides the identification rates for each lineup member for each age group for the video simultaneous lineup. For the simultaneous lineup the survival rates are the same as the identification rate (Pozzulo \& Lindsay, 1999). For adults the target was 1.33 times more likely to survive the video elimination lineup procedure than the simultaneous procedure, $\left(\chi^{2}(1, \mathrm{~N}=60)=5.46, p<\right.$ $.05)$. No significant differences for the survival rates of the target between the elimination and simultaneous video lineups were observed for the child groups.

\section{Choosers vs. non-choosers}

The data were collapsed across target-present and target-absent lineups to examine the influence of lineup procedure and age on choosing behaviour. Choosers were 
categorised as those who made a choice from a lineup and non-choosers were those who did not make a lineup choice. A hierarchical loglinear analysis (HILOG) was conducted with age (5-6 years, 9-10 years, adults), lineup procedure (simultaneous, sequential, elimination), and choice behaviour (chooser, non-chooser) as factors. This analysis revealed a model that retained all effects (Figure 2). The likelihood ratio of this model was $\left(\chi^{2}(0, N=540)=0, p=1\right)$.

\section{PLEASE INSERT FIGURE 2 ABOUT HERE}

Additional comparisons were performed to further analyse these results. There was a significant association between age and choosing behaviour, $\left(\chi^{2}(2, \mathrm{~N}=540)=24.75, p<\right.$ $.001) .5$ - to 6 -year olds were 1.44 times more likely than adults $\left(\chi^{2}(1, \mathrm{~N}=360)=24.41, p\right.$ $<.001)$ and 1.25 times more likely than 9 - to 10 -year olds to choose from a lineup $\left(\chi^{2}(1\right.$, $\mathrm{N}=360)=11.44, p<.01)$. However, the choosing behaviour of adults $(55 \%)$ and 9 - to10 -year olds $(63 \%)$ did not differ $\left(\chi^{2}(1, \mathrm{~N}=360)=2.59, p>.05\right)$.

The relationship between choosing behaviour and age was further analysed within lineup procedure. Age-related differences in choosing behaviour were found in the sequential, $\left(\chi^{2}(2, \mathrm{~N}=180)=8.46, p<.05\right)$, and elimination, $\left(\chi^{2}(2, \mathrm{~N}=180)=15.74, p<\right.$ .001 ), conditions. Choosing rates in the sequential condition were higher for 5- to 6-year olds compared to adults, $\left(\chi^{2}(1, \mathrm{~N}=120)=7.55, p<.01\right)$, and when compared to 9 - to 10 year olds, $\left(\chi^{2}(1, \mathrm{~N}=120)=5.71, p<.05\right)$. The choosing rate of adults and 9- to 10 - year olds in sequential lineups did not differ, $\left(\chi^{2}(1, \mathrm{~N}=120)=.14, p>.05\right) .5$ - to 6-year olds were 1.41 times more likely than adults and 1.33 times more likely than 9 - to 10 -year olds to choose a lineup member in a sequential lineup. For the elimination lineup, the only significant age-related association was for 5- to 6-year olds, who were 1.4 times 
more likely than adults to make a lineup choice $\left(\chi^{2}(1, \mathrm{~N}=120)=15.68, p<.001\right)$. No differences in choosing behaviour with simultaneous lineups were present $\left(\chi^{2}(1, N=\right.$ $180)=3.51, p>.05)$

The influence of lineup procedure on choosing rates within each age group was examined; no significant effects were present.

\section{Discussion}

The aim of this research was to examine the influence of alternative video lineup presentation procedures on children's and adult's identification accuracy.

As expected, and consistent with previous findings with photo lineups (Pozzulo \& Balfour, 2006; Pozzulo et al., 2008; Pozzulo et al., 2009; Pozzulo \& Lindsay, 1999), children's and adult correct identification rates in target-present lineups remained comparable in the simultaneous video and elimination video lineup conditions. The elimination lineup procedure also provides additional information about survival status (Pozzulo \& Lindsay, 1999). In the present study, for children and adults the target survived judgment one at a significantly higher rate than that of any other lineup member. Additionally, the target survived judgment one at a significantly higher rate than he was subsequently identified for both the elimination and simultaneous video lineups. However, in contrast to previous findings in the literature (Pozzulo et al., 2009; Pozzulo \& Lindsay, 1999), this pattern of responding was observed with the adult witnesses only in the present study.

In addition, the sequential video lineup was associated with a reduction in correct identification levels for both groups of children, but not for adults. Some previous 
studies have found that correct identification rates are not influenced by variations in lineup presentation procedure (Parker \& Ryan, 1993; Pozzulo \& Balfour, 2006; Pozzulo et al., 2009; Pozzulo \& Lindsay, 1998). On the other hand, other research has found that correct identification rates are reduced when a lineup is sequentially administered (Clark \& Godfrey, 2009; Flowe \& Ebbesen, 2007; Lindsay et al., 1997; McQuiston-Surrett et al., 2006; Steblay et al., 2001; Steblay et al., 2011).

The reduction in correct identification rates has been linked to the suggestion that the sequential lineup promotes the use of a conservative decision criterion (Ebbesen \& Flowe, 2002; Meissner, et al., 2005). Additionally, research also indicates that adults (Valentine et al., 2007) and older children (8- to 10-year olds; Parker \& Myers, 2001) make fewer correct identifications and more incorrect lineup rejections when the sequential lineup procedure employs strict rules (i.e., witnesses are informed that once a positive identification had been made the lineup will be terminated); as was the case in the current study. Research indicates however, that such procedural constraints are fundamental to producing the observed reduction in false identifications with a sequential lineup (Lindsay et al., 1991a; MacLin \& Phelan, 2007; McQuiston-Surrett et al., 2006). Looking at the distribution of identification responses in Table 1, 9- to 10-year olds reduced identification accuracy with a target-present sequential lineup seems to be linked with an increase in incorrect rejection rates. In contrast, 5- to 6-year olds reduced accuracy was due to them misidentify an innocent foil rather than making an incorrect lineup rejection. Closer examination of the data revealed that 5- to 6-year olds difficulty with the sequential lineup appeared to be due to their propensity to select the first picture presented (Lindsay et al., 1997), with $33 \%$ of 5 - to 6 -year-olds, $5 \%$ of adults, and $6 \%$ of 
9- to 10-year-olds, incorrectly selecting the first lineup member. Thus, although the identification accuracy of both groups of children appears to have been negatively influenced by the procedural modification used, the decision responses elicited appear to vary with witness age. The pattern of responding observed for the 9- to 10-year olds is consistent with a criterion shift explanation and strict procedural instructions promoting the use of a more conservative decision criterion. The pattern of responding observed for 5- to 6-year olds with a sequential lineup is not as easily accounted for by a criterion-shift explanation. Rather, the younger children may have experienced more difficulty comprehending and implementing the strict instructions implemented with the sequential lineup procedure.

In target-absent conditions, lineup procedure was not found to influence children's correct rejection rates. For adult witnesses, however, there was a trend towards higher correct rejection rates in video elimination lineups $(80 \%)$ compared with video simultaneous lineups $(60 \%)$. We found partial support for our prediction that the elimination video lineup would be the most effective procedure for increasing witnesses correct rejection rates. Although, the elimination lineup procedure was specifically designed for use with child witnesses (Pozzulo \& Lindsay, 1999), the finding that this procedure can also benefit the identification performance of adult witnesses is consistent with previous findings (Pozzulo \& Balfour; 2006; Pozzulo et al., 2008). The increased correct rejection rate that has been reported in the literature with a sequential line-up for adult witnesses however, was not replicated (for reviews see, Clark \& Godfrey, 2009; Steblay et al., 2001; Steblay et al., 2011). Consistent with previous research however, children's correct rejection rates were not facilitated with the sequential video lineup 
Faces in motion 26

procedure (Parker \& Ryan, 1993; Pozzulo \& Lindsay, 1998). A number of age-related differences were however observed. As expected, both groups of children were less likely than adults to correctly reject a target-absent lineup. Differences in correct rejection rates between the two child groups were, however, also observed, with 5- to 6- years less likely than 9- to 10-year olds to make a correct lineup rejection. Previous research studies have, however, typically reported no differences in correct rejection rates of similar age groups of children (e.g., Beresford \& Blades, 2006; Davies, Tarrant, \& Flin, 1989). Thus, the present study provides evidence that there is developmental improvement between the ages of 5- years and 10-years in children's ability to correctly reject a target-absent lineup.

Perhaps the 9- to 10-year olds are better able to resist the social demands placed upon them to select someone from a lineup compared to 5- to 6-year olds (Beal et al., 1995; King \& Yuille, 1987). Indeed, 5- to 6-year olds had a higher overall choosing rate than 9- to 10-year olds and adults, but choosing rates for adults and 9- to 10 -year olds did not differ. Alternatively, the younger children may have been less able than the older children to effectively use the additional information provided by the moving images (Beresford \& Blades, Havard et al., 2009; Skelton \& Hay, 2009). Therefore, it is plausible that the presentation of moving faces could have masked any beneficial effects of lineup procedure. Indeed, the correct rejection rates observed here for 9- to 10-year olds were considerably higher than those typically reported in the literature with photo lineups for similar aged children (e.g., Lindsay et al., 1997; Parker \& Ryan, 1993). Additionally, in contrast to previous findings, in the current study, 9- to 10-year olds' $(60 \%)$ and adults' $(60 \%)$ made correct rejections at equal rates with the simultaneous 
video lineup. Further studies should specifically manipulate the effect of movement across different lineup formats to examine if the viewing of faces in motion was indeed responsible for the age-related differences in correct rejections reported here.

Then again, differences may be linked to the procedural modifications associated with the implementation of moving images in the simultaneous and elimination video lineup procedures. In both of these procedures the participant was required to direct their focus towards each individual lineup member. This procedural modification may have evoked similar conditions as those in a sequential lineup, while excluding the anticipation that a yet-to be presented face may prove a better match to their memory of the target. Therefore, rather than promoting a shift in witness decision criterion, the modified procedure may have increased the opportunity for making absolute judgments (Lindsay \& Wells, 1985). Future research should be directed towards investigating the plausibility of these explanations.

As with any study, the current study has a number of possible limitations. In real eyewitness identification situations, there may be a considerable delay between the event and when a witness is asked to view a lineup. In the present study, a delay of only a few minutes (approximately 10 minutes) between the event and the identification task was employed. Therefore, the findings here for age, lineup procedure, and accuracy may differ relative to the length of delay. It is plausible that, with increasing delays the extra information that is provided when viewing faces in motion may help to increase witness identification accuracy. Additionally, although common to most eyewitness identification studies, a single target was employed. Thus the findings presented here may be specific to the target used. 
In sum, the current study has identified several interesting areas for continued research. Specifically, research is needed where the influence of movement is specifically manipulated across differing lineup presentation procedures. This research could help identify the age at which the viewing of moving faces aids witnesses' identification accuracy. On a similar level, research could usefully be aimed at investigating the effects that variations in the manipulation of the sequential lineup procedure (e.g., strict rules) have on children's identification performance. Perhaps, permitting children to view lineup members more than once reduces cognitive demand while also providing a greater opportunity for children to make comparisons between individual lineup members and their memory of the culprit, thus aiding identification accuracy. Such research could be used to further our understanding of the mechanisms underpinning the age-related differences in identification accuracy and to inform procedures for improving identifications in operational contexts.

\section{References}

Beal, C. R., Schmitt, K. L., \& Dekle, D. J, (1995). Eyewitness identification of children: Effects of absolute judgements, nonverbal response options, and event encoding. Law and Human Behavior, 19, 197-216. doi:10.1007/BF01499325

Beresford, J., \& Blades, M. (2006). Children's identification of faces from lineups: The effects of lineup presentation and instructions on accuracy. Journal of Applied Psychology, 91, 1102-1113. doi: 10.1037/0021-9010.91.5.1102

Brainerd, C. J., Reyna, V. F., \& Ceci, S. J. (2008). Developmental reversals in false 
memory: A review of data and theory. Psychological Bulletin, 134(3), 343-382. doi:10.1037/0033-2909.134.3.343

Bruce, V., Burton, A. M., \& Hancock, P. J. H. (2007). Remembering faces. In R. C. L. Read, D. F. Ross, \& M. Toglia (Eds.), Handbook of eyewitness psychology: Memory for people (Vol. 2, pp. 87- 100). Mahwah, NJ: Lawrence Erlbaum and Associates. doi:10.1002/acp.1450

Bruck, M., \& Ceci, S. J. (1999). The suggestibility of children's memory. Annual Review of Psychology, 50, 419-439. doi: 10.1146/annurev.psych.50.1.419

Ceci, S. J., \& Bruck, M. (1993). Suggestibility of the child witness: A historical review and synthesis. Psychological Bulletin, 113, 403-409. doi:10.1037/00332909.113.3.403

Ceci, S. J., \& Bruck, M. (1995). Jeopardy in the courtroom: A scientific analysis of children's testimony. Washington, D.C: American Psychological Association. Carlson, C. A., Gronlund, S. D., \& Clark, S. E. (2008). Lineup composition, suspect position, and the sequential lineup advantage. Journal of Experimental Psychology: Applied, 14(2), 118-128. doi: 10.1037/1076-898X.14.2.118

Clark, S. E., \& Godfrey, R. D. (2009). Eyewitness identification evidence and innocence risk. Psychonomic Bulletin \& Review, 16 (1), 22-42. doi:10.3758/PBR.16.1.22

Cutler, B. L., \& Fisher, R. P. (1990). Live lineups, videotaped lineups and photoarrays. Forensic Reports, 3, 439-448.

Cutler, B. L., \& Penrod, S. D. (1988). Improving the reliability of eyewitness identification: Lineup construction and presentation. Journal of Applied Psychology, 73, 281-290. doi:10.1037/0021-9010.72.4.629 
Faces in motion 30

Darling, S., Valentine, T., \& Memon, A. (2008). Selection of lineup foils in operational contexts. Applied Cognitive Psychology, 22, 159-169. doi:10.1002/acp.1366

Davies, G. M. (1996). Children's identification evidence. In S. L. Sporer, R. Malpass, \& G. Kohnken (Eds.), Psychological issues in eyewitness identification (pp. 233258). Mahwah, NJ: Erlbaum.

Davies, G. M., Tarrant, A. \& Flin, R. (1989). Close encounters of the witness kind: Children's memory for a simulated health inspection. British Journal of Psychology, 80, 415-429.

Dekle, D. J., Beal, C. R., Elliott, R., \& Huneycutt, D. (1996). Children as witnesses: A comparison of lineup versus showup identification methods. Applied Cognitive Psychology, 10, 1-12. doi:10.1002/(SICI)1099-0720(199602)10:1<1::AIDACP354>3.0.CO;2-Y

Dysart, J. E., \& Lindsay, R. C. L. (2001). A preidentification questioning effect: Serendipitously increasing correct rejections. Law and Human Behavior, 25, 155165. doi: 10.1023/A:1005693330921

Ebbesen, E. B., \& Flowe, H. D. (2002). Simultaneous v. sequential lineups: What do we really know? Retrieved from http://www.psy.ucsd.edu/\%7eeeb-bes-en/SimSeq.htm

Flowe, H., \& Ebbesen, E. (2007). The effect of lineup member similarity on recognition accuracy in simultaneous and sequential lineups. Law and Human Behavior, 31(1), 33-52. doi:10.1007/s10979-006-9045-9.

Goodman, G. S. (2006). Children's eyewitness memory: A modern history and 
Faces in motion 31

contemporary commentary. Journal of Social Issues, 62 (4), 811-832. doi:10.1111/j.1540-4560.2006.00488.x

Goodman, G. S., \& Reed, R. S. (1986). Age differences in eyewitness testimonies. Law and Human Behavior, 10, 317-332. doi:10.1007/BF01047344

Gronlund, S. D., Carlson, C. A., Dailey, S. B., \& Goodsell, C. A. (2009). Robustness of the sequential lineup advantage. Journal of Experimental Psychology: Applied, 15(2), 140-152. doi: 10.1037/a0015082

Havard, C., Memon, A., Clifford, B., \& Gabbert, F. (2009). A comparison of video and static photo lineups with child and adolescent witnesses. Applied Cognitive Psychology, 24, 1209-1221. doi:10.1002/acp.1645

Holliday, R. E., Reyna, V. F., \& Hayes, B. K. (2002). Memory processes underlying misinformation effects in child witnesses. Developmental Review, 22, 37-77. doi:10.1006/drev.2001.0534

Ihlebaek, C., Love, T. Eilertsen, D. E., \& Magnussen, S. (2003). Memory for a staged criminal event witnessed live and on video. Memory, 11, 319-327. doi: $10.1080 / 09658210244000018$

Juvenile offenders and victims: 2006 national report: Retrieved from http://ojjdp.ncjrs.gov/ojstatbb/nr2006/index.html

Kneller, W., Memon, A., \& Stevenage, S. (2001) Simultaneous and sequential lineups: Decision processes of accurate and inaccurate eyewitnesses. Applied Cognitive Psychology, 15, 659-671. doi:10.1002/acp.739 
King, M. A., \& Yuille, J. C. (1987). Suggestibility and the child witness. In S. J. Ceci, M. P. Toglia \& D. F. Ross (Eds), Children’s Eyewitness Memory (pp. 24-35). New York: Springer-Verlag.

Leippe, M. R., Romanczyk, A., \& Manion, A. P. (1991). Eyewitness memory for a touching experience: Accuracy differences between child and adult witnesses. Journal of Applied Psychology, 76, 367-379. doi:10.1037/0021-9010.76.3.367

Lindsay, R. C. L. \& Bellinger, K. (1999). Alternatives to the sequential lineup: The importance of controlling the pictures. Journal of Applied Psychology, 84, 315321. doi:10.1037/0021-9010.84.3.315

Lindsay, R. C. L., Lea, J. L., \& Fulford, J. A. (1991a). Sequential lineup presentation: Technique matters. Journal of Applied Psychology, 76, 741-745. doi:10.1037/0021-9010.76.5.741

Lindsay, R. C. L., Lea, J. A., Nosworthy, G. J., Fulford, J. A., Hector, J., LeVan, V., \& Seabrook, C. (1991b). Biased lineups: Sequential presentation reduces the problem. Journal of Applied Psychology, 76, 796-802. doi:10.1037/0021-9010.76.6.796

Lindsay, R. C. L., Pozzulo, J., Craig, W., Lee, K., \& Corber, S. (1997). Simultaneous lineups, sequential lineups, and showups: Eyewitness identification decisions of adults and children. Law and Human Behavior, 21, 391-402. 10.1023/A:1024807202926

Lindsay, R. C. L., \& Wells, G. L. (1985). Improving eyewitness identification from lineups: Simultaneous versus sequential lineup presentations. Journal of Applied Psychology,70, 556-564. doi:10.1037/0021-9010.70.3.556

Marin, B. V., Holmes, D. L., Guth, M., \& Kovac, P. (1979). The potential of children as 
eyewitnesses. Law and Human Behavior, 3, 295-305. doi:10.1007/BF01039808

MacLin, O. H., \& Phelan, C. M. (2007). PC_Eyewitness: Evaluating the New Jersey method. Behavior Research Methods, 39, 242-247. doi: 10.3758/BF03193154

MacLin, O. H., Zimmerman, L. A., \& Malpass, R. S. (2005). Pc_Eyewitness and the sequential superiority effect: Computer-based lineup administration. Law and Human Behavior, 29, 303-321. doi:10.1007/s10979-005-3319-5

McQuiston-Surrett, D., Malpass, R. S., \& Tredoux, C. G. (2006). Sequential vs. simultaneous lineups: A review of methods, data, and theory. Psychology, Public Policy \& Law, 12, 137-169. doi:10.1037/1076-8971.12.2.137

Meissner, C. A., Tredoux, C. G., Parker, J. F., \& MacLin, O. H. (2005). Eyewitness decisions in simultaneous and sequential lineups: A dual-process signal detection theory analysis. Memory \& Cognition, 33, 783-792.

Morris, C. D., Bransford, J. D., \& Franks, J. J. (1977). Levels of processing versus transfer-appropriate processing. Journal of Verbal Learning and Verbal Behavior, 16, 519-533. doi:10.1016/S0022-5371(77)80016-9

O’Toole, A. J., Roark, D. A., \& Abdi, H. (2002). Recognizing moving faces: A psychological and neural synthesis. Trends in Cognitive Sciences, 6, 261-266. doi:10.1016/S1364-6613(02)01908-3

Parker, J. F., \& Carranza, L. E. (1989). Eyewitness testimony of children in target-present and target-absent lineups. Law and Human Behavior, 13, 133-149. doi:10.1007/BF01055920

Parker, J. F., \& Myers, A. (2001). Attempts to improve children's identifications from sequential presentation lineups. Journal of Applied Social Psychology, 31, 796- 
Faces in motion 34

815. doi:10.1111/j.1559-1816.2001.tb01414.x

Parker, J. F., \& Ryan, V. (1993). An attempt to reduce guessing behavior in children's and adults' eyewitness identifications. Law and Human Behavior, 17, 11-26. doi:10.1007/BF01044534

Pike, G., Brace, N., \& Kynan, S. (2002). The visual identification of suspects: Procedures and practice (Briefing Note 2/02). London: Home Office.

Police and Criminal Evidence Act 1984 and accompanying Codes of Practice (2008). Retrieved from: http://www.homeoffice.gov.uk/publications/police/operationalpolicing/pace-codes/

Pozzulo, J. D. (2007). Lineup identification by children. In R. C. L. Lindsay, D. F. Ross, J. D. Read, \& M. P. Toglia (Eds.), Handbook of eyewitness psychology: Memory for people (Vol. 2, pp. 283-307). Mahwah, NJ: Lawrence Erlbaum and Associates. doi:10.1002/acp.1450

Pozzulo, J. D., \& Balfour, J. (2006). Children's and adults' eyewitness identification accuracy when a culprit changes his appearance: Comparing simultaneous and elimination line-up procedures. Legal and Criminological Psychology, 11, 25-34. doi: $10.1348 / 135532505 X 52626$

Pozzulo, J. D., Crescini, C., \& Panton, T. (2008). Does methodology matter in eyewitness identification research?: The effect of live versus video exposure on eyewitness identification accuracy. International Journal of Law and Psychiatry, 31, 430437. doi:10.1016/j.ijlp.2008.08.006

Pozzulo, J. D., \& Dempsey, J. (2006). Biased lineup instructions: Examining the effects of pressure on children's and adults' eyewitness identification accuracy. Journal 
Faces in motion 35

of Applied Social Psychology, 36, 1381-1394. doi:10.1111/j.00219029.2006.00064.x

Pozzulo, J. D., Dempsey, J., Corey, S., Girardi, A., Lawandi, A., \& Aston, C. (2008). Can a lineup procedure designed for child witnesses work for adults? Comparing simultaneous, sequential, and elimination lineup procedures. Journal of Applied Social Psychology, 38, 2195-2209. doi:10.1111/j.1559-1816.2008.00387.x

Pozzulo, J. D., \& Dempsey, J., \& Crescini, C. (2009). Preschoolers' person description and identification accuracy: A comparison of the simultaneous and elimination lineup procedures. Journal of Applied Developmental Psychology, 30(6), 667676. doi:10.1016/j.appdev.2009.01.004

Pozzulo, J. D., \& Lindsay, R. C. L. (1997). Increasing correct identifications by children. Expert Evidence, 5, 126-132. doi:10.1023/A:1008875802767

Pozzulo, J. D., \& Lindsay, R. C. L. (1998). Identification accuracy of Children versus Adults: A meta-analysis. Law and Human Behavior, 22, 549-570. doi: 10.1023/A:1025739514042

Pozzulo, J. D., \& Lindsay, R. C. L. (1999). Elimination lineups: an improved identification procedure for child eyewitnesses. Journal of Applied Psychology, 84, 167-176. doi:10.1037/0021-9010.84.2.167

Pozzulo, J. D., \& Warren, L. (2003). Descriptions and identifications of strangers by youth and adult eyewitnesses. Journal of Applied Psychology, 88, 315-323. doi:10.1037/0021-9010.88.2.315

Skelton, F., \& Hay, D. (2008). Do children utilize motion when recognizing faces? Visual Cognition, 16, 419-429. doi:10.1080/13506280701577496 
Faces in motion 36

Sporer, S. L. (1993). Eyewitness identification accuracy, confidence and decision times in simultaneous and sequential lineups. Journal of Applied Psychology, 78, 22-33. doi:10.1037/0021-9010.78.1.22

Steblay, N., Dysart, J., Fulero, S., Lindsay, R. C. L. (2001). Eyewitness accuracy rates in sequential and simultaneous lineup presentations: A meta-analytic comparison. Law and Human Behavior, 25, 459-473. doi:10.1023/A:1012888715007

Steblay, N., Dysart, J., \& Wells, G. (2011). Seventy-two tests of the sequential lineup superiority effect: A meta-analysis and policy discussion. Psychology, Public Policy, \& Law, 17(1), 99-139. doi: 10.1037/a0021650

Tredoux, C. G. (1998). Statistical inference on measures of lineup fairness. Law and Human Behavior, 22, 217-237. doi: 10.1023/A:1025746220886

Ullman, S. (1979). The interpretation of visual motion. Cambridge, MA: MIT Press.

Valentine, T., Darling, S., \& Memon, A. (2007). Do strict rules and moving images increase the reliability of sequential lineup procedures? Applied Cognitive Psychology, 21, 933-949. doi:10.1002/acp.1306

Wells, G. L., Memon, A., \& Penrod, S. D. (2006). Eyewitness evidence: Improving its probative value. Psychological Science in the Public Interest, 7, 45-75. doi:10.1111/j.1529-1006.2006.00027.x

Yuille, J. C. (1993). We must study forensic eyewitnesses to know about them. American Psychologist, 48, 572-573. 
Faces in motion 37

Table 1

Proportion of correct and incorrect identification decisions by age and lineup procedure

\begin{tabular}{|c|c|c|c|c|c|c|c|c|c|}
\hline \multirow[b]{3}{*}{ Decision } & \multirow{2}{*}{\multicolumn{3}{|c|}{ Simultaneous }} & \multicolumn{3}{|c|}{ Lineup procedure } & & & \\
\hline & & & & \multicolumn{3}{|c|}{ Elimination } & \multicolumn{3}{|c|}{ Sequential } \\
\hline & $5-6$ & $9-10$ & Adults & $5-6$ & $9-10$ & Adults & $5-6$ & $9-10$ & Adults \\
\hline \multicolumn{10}{|l|}{ Target-present } \\
\hline \multirow[t]{2}{*}{ Correct identification } & 0.60 & 0.73 & 0.70 & 0.57 & 0.63 & 0.63 & 0.30 & 0.47 & 0.83 \\
\hline & (18) & (22) & $(21)$ & (17) & (19) & (19) & $(9)$ & (14) & $(25)$ \\
\hline \multirow[t]{2}{*}{ False alarm } & 0.33 & 0.20 & 0.17 & 0.33 & 0.20 & 0.07 & 0.57 & 0.23 & 0.03 \\
\hline & $(10)$ & $(6)$ & $(5)$ & $(10)$ & $(6)$ & $(2)$ & (17) & $(7)$ & $(1)$ \\
\hline \multirow[t]{2}{*}{ Incorrect rejection } & 0.07 & 0.07 & 0.13 & 0.10 & 0.17 & 0.30 & 0.13 & 0.30 & 0.13 \\
\hline & $(2)$ & $(2)$ & (4) & (3) & $(5)$ & $(9)$ & $(4)$ & $(9)$ & (4) \\
\hline \multicolumn{10}{|l|}{ Target absent } \\
\hline \multirow[t]{2}{*}{ Correct rejection } & 0.37 & 0.60 & 0.60 & 0.33 & 0.57 & 0.80 & 0.27 & 0.50 & 0.73 \\
\hline & (11) & (18) & (18) & (10) & (17) & (24) & $(8)$ & (15) & (22) \\
\hline \multirow[t]{2}{*}{ False alarm } & 0.63 & 0.40 & 0.40 & 0.67 & 0.43 & 0.20 & 0.73 & 0.50 & 0.27 \\
\hline & (19) & (12) & (12) & $(20)$ & (13) & $(6)$ & (22) & (15) & $(8)$ \\
\hline
\end{tabular}


Faces in motion 38

Table 2. Video elimination lineup (target-present lineups only): Proportion of line-up member survival rates at judgment 1 (identification rates at judgement 2) by age group.

\begin{tabular}{|c|c|c|c|c|c|c|c|}
\hline \multicolumn{8}{|c|}{ Line-up member } \\
\hline & & 1 & 2 & 3 & 4 & 5 & 6 \\
\hline \multirow[t]{3}{*}{ Elimination } & 5- to 6-year olds & $.13(.13)$ & $.07(.03)$ & $.10(.07)$ & $.60(.57)$ & $.07(.07)$ & $.03(.03)$ \\
\hline & 9 - to 10 -year olds & - & $.10(.10)$ & $.07(.03)$ & $.80(.63)$ & $.03(.03)$ & - \\
\hline & Adults & $.03(.03)$ & $.03(.03)$ & & $.93(.63)$ & & - \\
\hline \multirow[t]{3}{*}{ Simultaneous } & 5- to 6-year olds & .03 & .03 & .10 & .60 & .03 & .13 \\
\hline & 9 - to 10 -year olds & .03 & & .07 & .73 & .03 & .03 \\
\hline & Adults & .03 & .03 & .07 & .70 & .03 & - \\
\hline
\end{tabular}

Note. $n=30$. Lineup member 4 was the target. Survival rate information is not possible in the simultaneous or sequential lineups (the survival rate is the same as the identification rate). 